\title{
AN ONLINE 3D DATABASE SYSTEM FOR ENDANGERED ARCHITECTURAL AND ARCHAEOLOGICAL HERITAGE IN THE SOUTH-EASTERN MEDITERRANEAN
}

\author{
${ }^{1}$ D.Abate, ${ }^{1}$ A.Avgousti, ${ }^{1}$ M.Faka, ${ }^{1}$ S.Hermon, ${ }^{1}$ N.Bakirtzis, ${ }^{2}$ P. Christofi \\ ${ }^{1}$ Science and Technology in Archaeology Research Center - The Cyprus Institute, Nicosia \\ (d.abate, a.avgousti, m.faka, s.hermon, n.bakirtzis)@cyi.ac.cy \\ ${ }^{2}$ Department of Antiquities, Nicosia, Cyprus \\ pchristofi@da.mcw.gov.cy
}

\section{Commission II}

KEY WORDS: Risk Management, Endangered Heritage, Architectural Heritage, Cypriot and East-Mediterranean Heritage Sites, Digital Preservation

\begin{abstract}
:
The World Heritage Convention, drawn by various international bodies in 1972, was designed to protect cultural or natural places of outstanding universal value so that future generations may be able to enjoy them. Responding to these principles as well as to the Charter on the Preservation of Digital heritage (Vancouver, 2003), this multidisciplinary project, which involves archaeologists, art historians, conservators and computer scientists, aims to create an open access, 3D interactive online geo-database of endangered architectural and archaeological heritage in the South Eastern Mediterranean basin; a region of tremendous cultural importance whose rech heritage is unfortunately threatened by both natural and human factors. A wide range of 3D modelling and topographic techniques have been applied to create accurate reconstructions of heritage sites, enriched by a extensive array of metadata.
\end{abstract}

\section{INTRODUCTION}

\subsection{Heritage at Risk}

A large number of significant heritage sites around the world are fragile assets, faced with different and continuous challenges. Uncontrolled urban development, tourism, inappropriate site management, pollution, natural disasters, looting and war conflicts are some of the risks threatening heritage. The UNESCO Convention for the Protection of the World Cultural and Natural Heritage (1972) is one of the main efforts for saving threatened archaeological or artistic sites.

Especially built cultural heritage is vulnerable to the forces of nature in many different ways. Earthquakes, flooding, tsunamis, ranked as sudden, unpredictable and catastrophic events, have an immediate and destructive impact on built heritage sites.

However, the abovementioned threats by natural disasters are only circumstantial and unpredictable, while the challenges facing heritage conservation are a daily reality (Will and Meier, 2007). Rapid economic development, taking place under the boost of world population growth and increasing industrialisation, leads to faster and larger urban expansion with its associated burden on the historical environment. Faced with social and economic change, historic buildings that are no longer in use become endangered by neglect and deterioration or simply surrenders to the pressures of real estate development.Similarly, without sufficient protection, many archaeological sites are affected by looters and illegal excavations. From this perspective, human-inflicted disasters are significantly more distractive than natural disasters. War, civil disorder, terrorism and vandalism are human factors that contribute to the intentional or accidental destruction of heritage sites. Of these threats, armed conflict remains particularly disturbing (Teijgeler, 2006).

Today, the world is losing heritage sites at a rate faster than it is able to preserve them. Nonetheless, thanks to the technological advances observed in the field of 3D modelling techniques, which provide reliable, feasible, accurate and portable tools and methodologies, it is possible to preserve the historical memory of the built heritage at the time of the acquisition in a digital format (Gruen, et al., 2004; El Hakim, et al., 2008; Guidi, et al., 2009; Remondino, 2011, Fangi, 2015).

The Online 3D Database System for Endangered architectural and archaeological Heritage in the south Eastern MEediterRAnea Area (EpHEMERA) is intended to serve as an infrastructure where it is possible to:

- Visualize online and through standard web browser 3D architectural and archaeological models classified according to a specific type of risk;

- Query the database system and retrieve metadata attached to each single virtual object (Ronzino, et al., 2012);

- Extract geometric and morphological information.

\subsection{Related Works}

The current recording and archiving of heritage-sites activities can be divided in two main categories or domains. One is identified by those initiatives foreseen as preventive actions aiming to digitize specific sites or monuments depending to their risk assessment. The second one focuses on the reconstruction of lost heritage through existing data collected by various means. 
Today, despite the lack of a common and structured effort, the amount of digital born data on heritage sites is growing fast. Although the cost of $3 \mathrm{D}$ scanners still represents a huge limitation, the latest improvements in image based modelling algorithms and cameras allow exploiting a feasible, portable and affordable technique which can provide reliable and accurate geometrical and morphological data (El-Hakim, et al 2008; Wenzel, et al., 2013; Luhmann, et al., 2014; Remondino, et al., 2014;).

A worldwide well known initiative is the one led by the Cyark Foundation which aims to preserve digitally a large number of heritage sites at risk. Specifically, the ongoing CyArk 500 initiative is a global effort to digitally preserve 500 of the most important world heritage sites. This will be accomplished therough the utilization of new technologies, both image and range based, to quickly and cost-effectively digitally preserve these sites (Kacyra, 2009).

More recently, another big effort and, at the same time, a major challenge facing the research community, is the one connected with the de facto lost heritage, which may have occurred due to natural disasters or men-made actions such as in conflict war zones.

The CIPA sponsored open access database for saving the heritage of Syria (Silver, et al., 2016) gathers data collected during various projects in Syria, up to the outburst of armed hostilities in 2011. The CIPA project creates a useful database to support the protection, preservation, restoration and reconstruction strategies as well as to operate at a material level, providing information for the treatment of original and historical surfaces, suggesting their protection, their structural consolidation and, when necessary, their partial reconstruction.

Another remarkable activity is represented by the Mosul Project, recently renamed Project Rekrei. It is an infrastructure for managing crowd-sourced reconstructions of lost heritage worldwide. This project strives to preserve the memory of lost cultural heritage through the means of digital restoration. Using crowdsourced photographs from experts, tourists, or anyone with digital imagery, the project applies photogrammetric techniques to create three-dimensional representations of heritage that has been lost around the globe due to natural calamities or caused by human activity (Coughenour and Vincent, 2015; Vincent, et al., 2015).

\section{THE EPHEMERA DIGITIZATION STRATEGY}

The above-mentioned initiatives served as intellectual basis for setting-up the EPHEMERA initiative described below. It has been created as a response to the need for centralised access to 3D digitisation intiatives concluded or on-going, by the STARC team of The Cyprus Institute. These STARC-led collaborative efforts aim at the systematic recording of architectural heritage on the island, with a particular focus on heritage at risk (such as exposure to looters, abandonment, natural degrade, etc.). The following case studies represent three distinct situations which reflect architectural and archaeological heritage at risk today in Cyprus and Israel.

\subsection{The Givati Parking Lot Excavation and Jerusalem Urban Expansion}

The Givati Parking lot (Hanyon Givati) is a large archaeological site located in the City of David neighbourhood in Jerusalem (Figure 1). The excavation started in 2007 when, during the construction of a new parking lot adjacent the Dung Gate of Jerusalem, monumental evidences appeared. Since then, the Israel Antiquities Authority (IAA) is conducting an extensive rescue campaign to uncover and document all structures and finds (Ben-Ami and Tchekhanovets, 2011).

Today the site consists of several monumental buildings overlapping on different historical layers and extending over an area of $\sim 30000$ square meters, reaching a depth of more than 10 meters from the current street level (Ben-Ami and Tchekhanovets, 2016).

In almost 10 years of research, archaeologists have been able to identify and classify structures ranging from the Iron Age to the Hellenistic, Byzantine and Roman periods (Ben-Ami, 2014).

Due to the urgency of the salvage excavation and the need for a detailed record of the geomorphological features of the site, which is located on a steep slope, two range based surveys were performed during April 2013 and December 2015 exploiting a phase shift Terrestrial Laser Scanner (TLS) and a total station as topographical support.

The 4D database consisted respectively of 43 (April 2013) and 125 range maps (2015) The difference in the overall amount of stations is due to the progress of the excavation among a two years $\Delta$-Time (Figure 2). The average resolution for the final point clouds have been estimated in $5 \mathrm{~mm}(\mathrm{X}-\mathrm{Y})$.

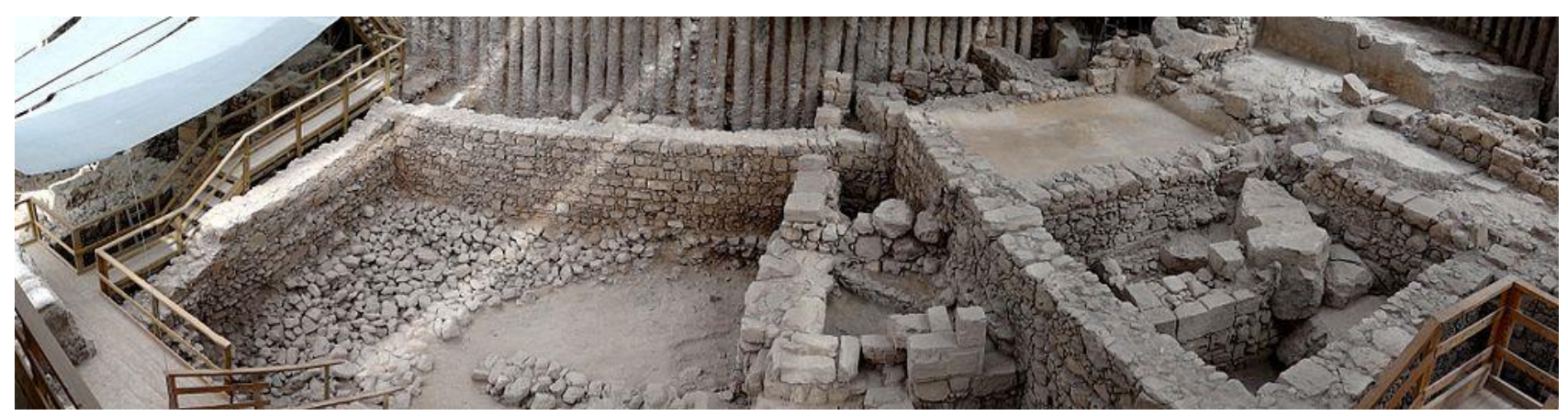

Figure 1: Givati Parking Excavation, Jerusalem, Panoramic View (source Wikipedia) 


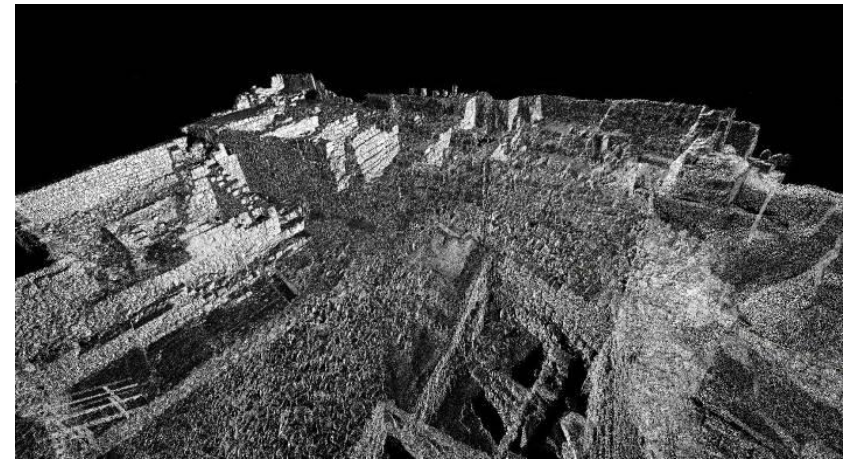

Figure 2: 3D model of Givati Parking Lot Excavation (December 2015 Survey)

All the single range maps have been then aligned in a single reference system following a common processing pipeline (Mills, 2011).

The data have been then referenced in the Israeli Transverse Mercator Reference System (ITM).

\subsection{Ayia Marina in Deryneia, UN Controlled Buffer Zone, Cyprus}

The church of Ayia Marina is located in the eastern edge of Cyprus, Derynia, (Famagusta district) situated within the Buffer Zone controlled by the United Nations peacekeeping forces. Since the creation of the buffer zone in 1964 and its extension in 1974, the area and the church itself is inaccessible to the general public without a proper permit issued by the UN (Hadjisavvas, S., 2004; Chotzakoglou, C., 2008).

A late $11^{\text {th }}$ century date has been proposed by (Procopiou, 2006) for the chapel. The church is one of the oldest within the Famagusta region. Originally, it was a single-domed chapel without a narthex. Later a domed narthex was added to the west, and probably during the $14^{\text {th }}$ century, a vaulted single-aisle chapel was attached to the south (MKE, 1984-1991). Today the ecclesiastical complex consists of two equal-sized small churches linked by passages (Figure 3 ).

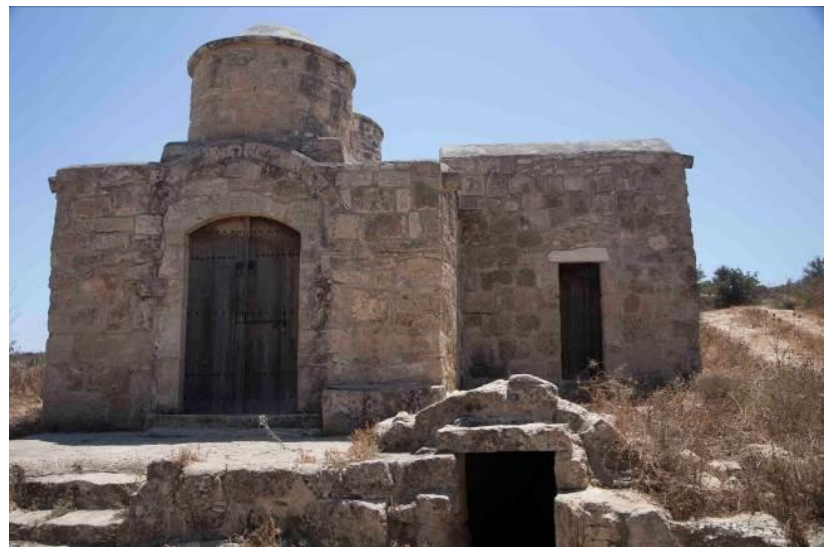

Figure 3: Church of Ayia Marina, Deryneia, Exterior

Constraints and challenges such as strict rules established by the UN forces, limited working time available to perform the digitization tasks, and extremely hot weather conditions which might have hampered the topographic devices functions, made the survey campaign extremely challenging.
A comprehensive set of techniques, namely Photogrammetry, Terrestrial Laser Scanning, GPS and Total Station, were applied in this unique opportunity of documenting this religious building located in an accessible area.

A Structure from Motion (SfM) acquisition was performed using a Canon EOS 6D camera equipped with a Tamron 24-70 f2.8 lens fixed with an insulation tape at $50 \mathrm{~mm}$ and a Canon 600D, 18-megapixel sensor device, equipped with a Canon EF

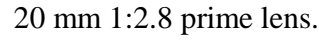

A total of 964 pictures were taken by moving around the structure yielding a baseline of $30 \mathrm{~cm}$. For the acquisition of the roof, the camera was placed on an extendible pole up to 5-8 meters height (Hermon, et al., 2013).

The camera's autofocus and image stabilizer were disabled in order to avoid unwanted changes of interior orientation parameters during the photogrammetric survey and insure its rigidity. All acquisition protocols were performed with the same photographic parameter setup (Toschi et al., 2014).

Each photo was pre-processed to equalize its colours according to a colour checkerboard, and the background has been masked to facilitate and improve the quality of the alignment process.

Subsequently the image dataset has been imported in Agisoft Photoscan. The 3D model, consisting of $\sim 21$ milions points has been finally scaled in relation to the topographic measurements collected previously (Figure 4).

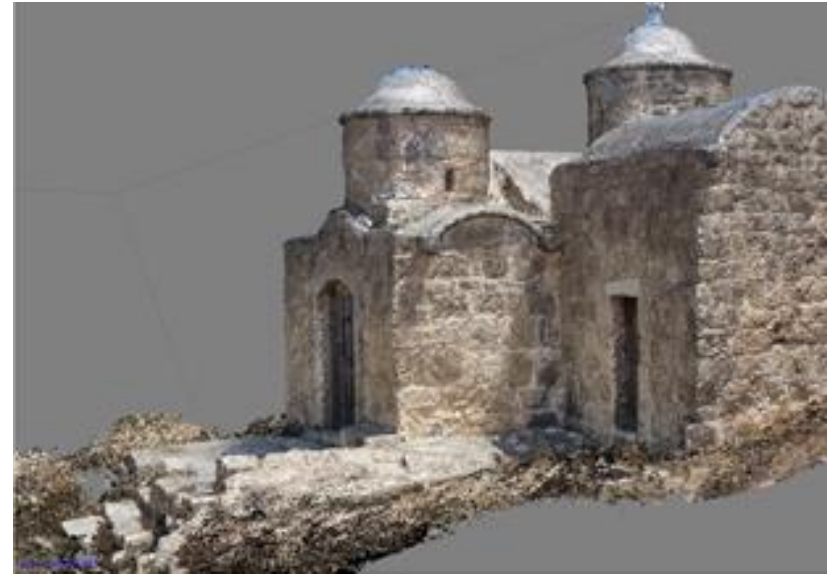

Figure 4: 3D model of Ayia Marina

The range based survey consisted of 14 scans acquired with a phase shift TLS with an average resolution of $5 \mathrm{~mm}$. The point clouds alignment was performed both using reflective targets and cloud costraints (ICP algorithms). To further improve the final registration, total station points were embedded in the pipeline together with GPS data to georeference the 3D model (Cyprus Geodetic Reference System 1993 - CGRS93).

\subsection{Rescue Excavation at St. Francis Street in Larnaca}

The Catholic Church, known today as Terra Santa but officially dedicated to Saint Mary of Graces and the adjacent convent were reportedly founded in 1596, by Saint Francis battalion, to host latin pilgrims on their way to the Holy Land. Two centuries later, in 1724, the church was demolished and rebuilt. The present church was erected and consecrated in 1842 (Jeffery, 1918; Hadjilyra, 2009). 
During planned road works carried out by the Larnaca Sewerage and Drainage Board in the area surrounding the religious complex, archaeological remains and structures belonging to phases of the monastery dating from the late $13^{\text {th }}$ early $14^{\text {th }}$ century were discovered. The excavation was held in a trench of $50 \mathrm{~m} \times 5 \mathrm{~m} \times 1.5 \mathrm{~m}$ (Figure 5).

However, the importance of the road for the local transportation system necessitated its urgent re-opening to regular traffic.,As a result, the Larnaca Municipality, in agreement with the Cyprus Department of Antiquities, decided to backfill all the archaeological finds under layers of sand (approximately 500 cubic meter) and asphalt. Nonetheless, in accordance with the policies of the Department of Antiquities, an adequate documentation was performed to properly provide sufficient documentation date to allow further studies and scientific analysis.

Both image based and range based modelling techniques were used to digitize the archaeological trench, coupled with a GPS data survey. A camera network was planned with the main aim to obtain a ground sample distance (GSD) of $0.6 \mathrm{~mm}$.

A Canon 600D, 18-megapixel sensor device, equipped with a

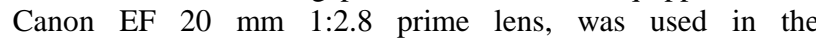

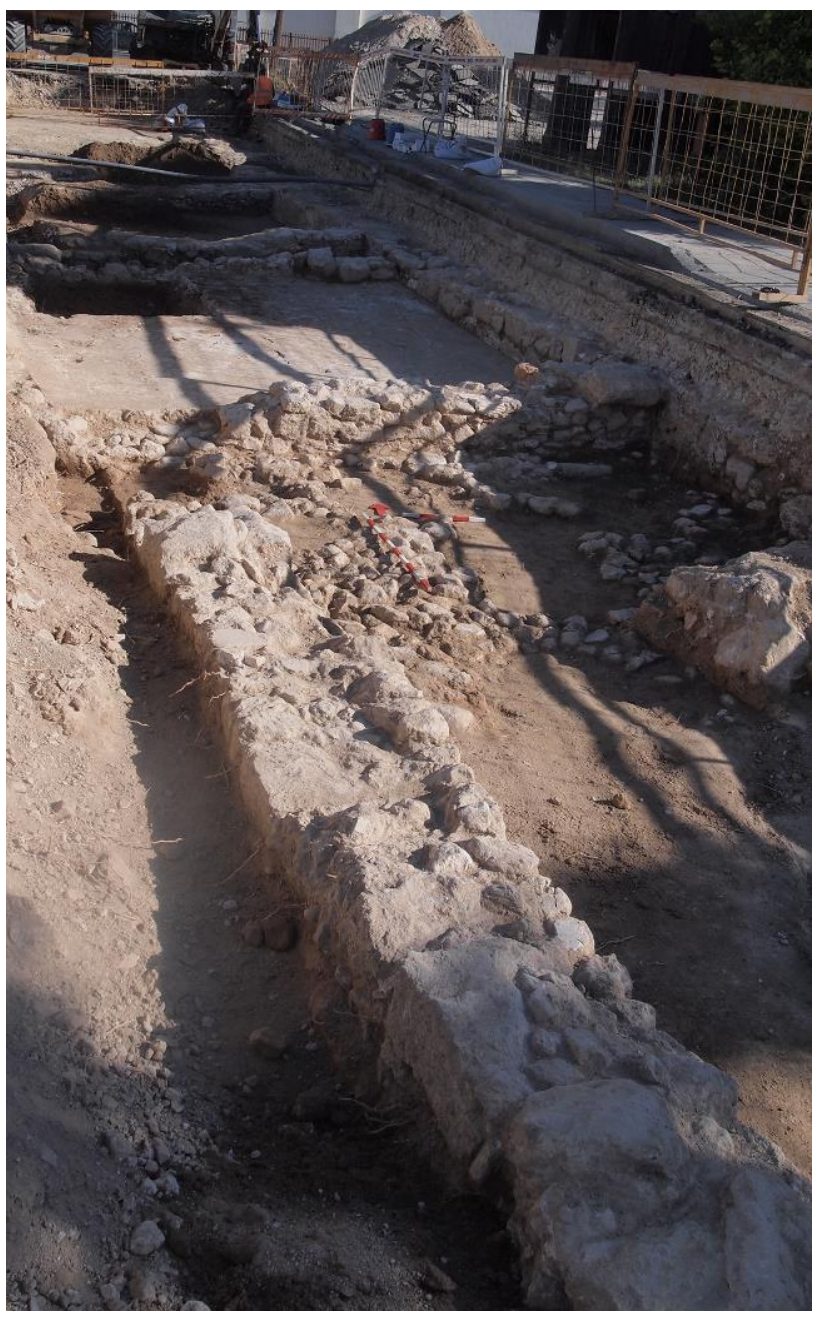

photogrammetric survey. 670 images were acquired and processed with Agisoft Photoscan in order to produce a georeferenced 3D model of the excavation (Figure 6) and a high-resolution ortho-photo of the site with a pixel dimension of $1 \mathrm{~mm}$ (Figure 7).

The range based survey was carried out with a phase shift TLS in order to create an accurate sub-centrimetic 3D geometry of the site needed for further analytic studies. Sixty four (64) point clouds have been acquired in a two days campaign. The optimized final model will be further used for the extraction of traditional CAD drawings. Finally, a GPS survey has been performed to georeference in the Cyprus Geodetic Reference System 1993 (CGRS93) both the 3D models retrieved from image based modelling and from TLS campaign.

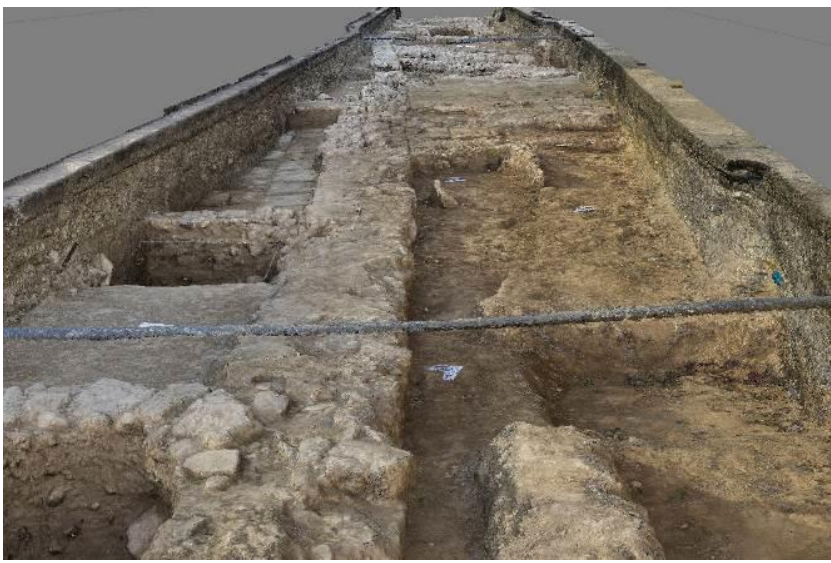

Figure 6: 3D Model of St. Francis Street Excavation Area, Larnaca

\section{ONLINE 3D DATABASE SYSTEM FOR ENDANGERED ARCHITECTURAL AND ARCHAEOLOGICAL HERITAGE IN THE SOUTH-EASTERN MEDITERRANEAN AREA (EPHEMERA)}

\subsection{Database Architecture}

The EPHEMERA database infrastructure (http://ephemera.cyi.ac.cy) is being developed addressing the Open Access (OA) guidelines which refer to the practice of providing online access to scientific information (H2020 Programme, 2016). It has been built customizing the open source Drupal Content Management Framework (CMF). Drupal (Kawano, 2013) is highly configurable and is an application development framework which can:

- dynamically handle multimedia files and 3D models;

- be adapted and extended according to the project's needs;

- $\quad$ count on a large community of developers and users.

Figure 5: St. Francis Street Excavation, Larnaca, the Trench Exposed 


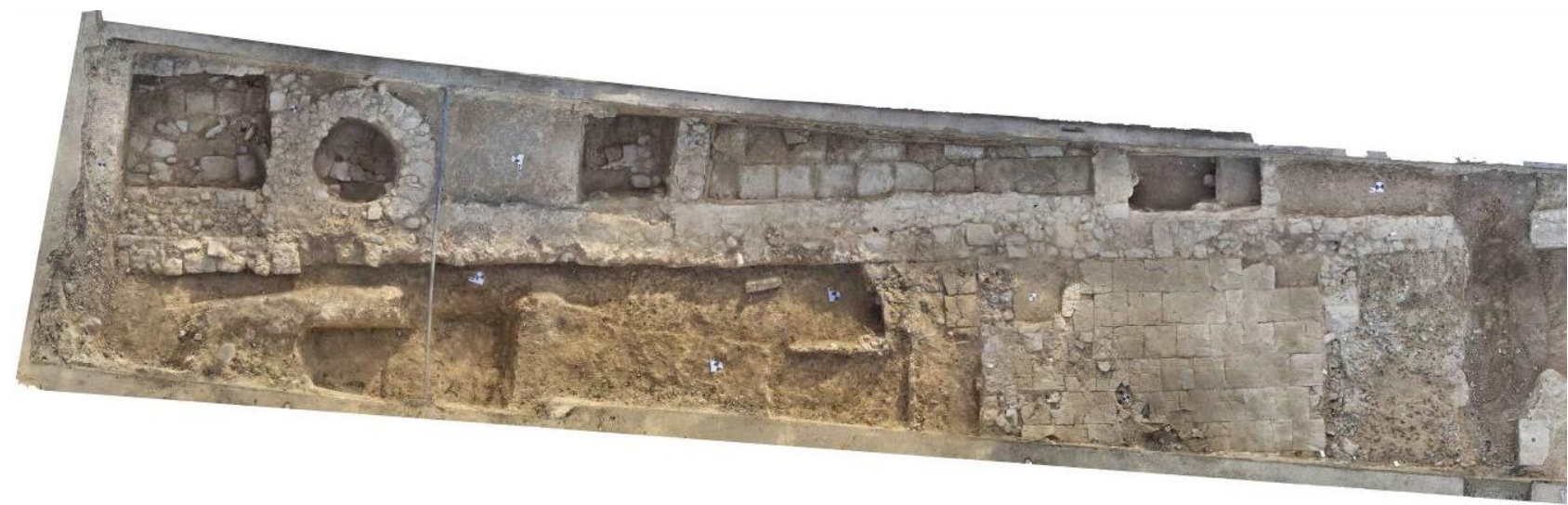

Figure 7: St. Francis Street Excavation, Larnaca, Orthophoto, Detail

A key feature of the system is the ability to manage highresolution large and complex 3D models on the web. A dedicated Network Attached Storage (NAS) server (Gibson and Van Meter, 2001) installed on the "CyTera" HPC infrastructure allows the system to handle a huge amount of 3D data, and other media files. The storage system is scalable and expandable, depending on the availability of new 3D models (Figure 8).

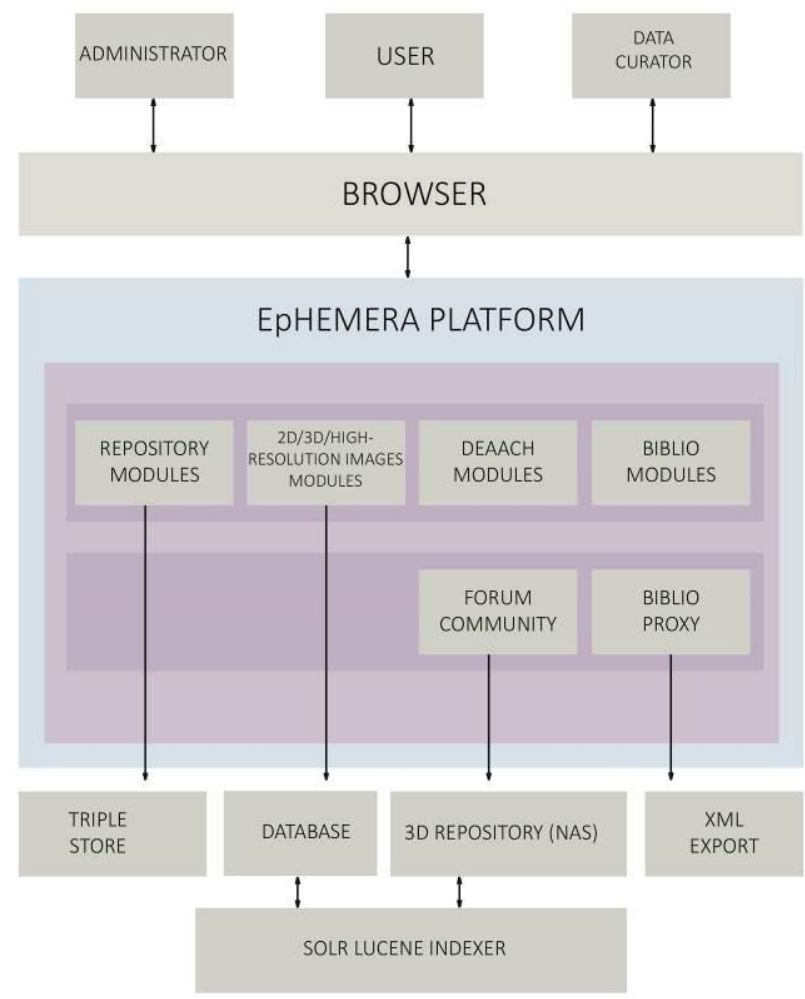

Figure 8: Drupal Database Schema

With the main aim to support 3D models and their relevant metadata (text file, pictures, panoramic images, Gigapixel images, video, external links and resources), and to further map their attributes to existing cultural heritage metadata schema, a Content Type has been developed (Velios, 2011). More than 45 fields and a dedicated taxonomy connected to the customized Content Type has then been created.

\subsection{Collection Management System}

The current beta version supports a semi automatic data import approach. After uploading 3D contents and all relevant metadata, a procedure takes place for the validation of the appropriateness of the information provided. The system will then generate for each approved entry a unique web page and a URI which hosts all data and metadata for the specific object. It is planned that the next system release will feature a fully automatic content upload and provide export options (XML, JSON) based to in force Intellectual Property Rights (IPR).

As stated by the principles of the London Charter for the Computer-Based Visualisation of Cultural Heritage aimed to ensure the methodological rigour of computer-based visualization as a means of researching and communicating cultural heritage, the data-upload-web form enables the user to provide all the information needed for the $3 \mathrm{D}$ online visualization set-up (Denard 2012). The form contains several fields such as title, description, country, location categories, publisher, owner, digitization technical features, 3D models, images, etc. Each field can store one type of data (text, file, image, etc) and every field is mapped in LIDO which is an XML harvesting schema for supporting the full range of descriptive information about heritage. (McKenna and Stein, 2011).

\subsection{Searching Tools and Users Privileges}

The database query system has been structured with multiple search strategies:

(i) A simple and an advanced search option, powered by Apache Solr Search, that indexes the database allowing the user to search and retrieve all content stored (Smiley and Plugh, 2011).

(ii) A facet search interface which allows the user to access information by applying multiple filters.

(iii) An interactive map displaing all monuments geolocation on a graphic interface (Figure 9).

Three types of users have been a priori identified and privileges have been respectively assigned:

(i) Non-authenticate or Anonymous. By default anyone who access the EPHEMERA web portal. The user can browse the database with view only permissions.

(ii) Registered. This is an authenticated user who can login into the system to create or edit content through a dedicated user interface. 
(iii) Data Curator. The system administrator has access to all content with comprehensive privileges.

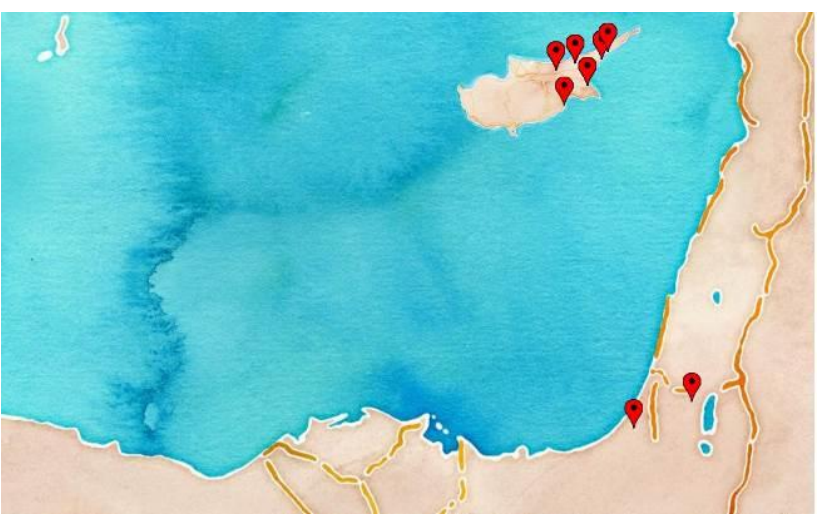

Figure 9: Interactive Map

\subsection{Long-Term Data Preservation}

Along with the main aim of the project which is to virtually provide access to endangered or not accessible heritage sites, another goal is represented by the preservation of digital data in accordance with the 2003 Charter on the Preservation of Digital Heritage (Vacouver). Article 2 indeed recalls that "|The purpose of preserving the digital heritage is to ensure that it remains accessible to the public..". Article 3 states instead, that "The world's digital heritage is at risk of being lost to posterity".

According to these assumptions, XML language has been used to archive information due to its technical features and its portability which facilitate data migration and data transparence (Müller, et al, 2003).

Authorized users will be able to export data in XML format which is both human and machine-readable.

\subsection{Online 3D Viewer}

Different approaches have been proposed in literature for the online visualization of large $3 \mathrm{D}$ datasets. In the past years the scientific community focused on the rendering and visualization, in real-time and possibly via web, of large 3D models. (Gobbetti, et al., 2006; Andujar and Brunet, 2008; Yoon, et al., 2008; Di Benedetto, et al., 2009).

Generally a hierarchical and local representation of geometry and texture is employed (LOD approach).

A simpler geometric representation for far geometries is coupled with impostor-like techniques, raytracing and GPU programming for the textures representation (Buchholz and Döllner, 2005; Andujar, et al., 2007; Cignoni et al., 2007). Thus, many remote rendering platforms have been developed with different rendering approaches.

HPC infrastructures have been used for multi-user access to a repository of $3 \mathrm{D}$ models and metadata exploiting different applications in relation to different goals (Abate, et al., 2012; Jiménez Fernandez-Palacios, et al., 2013).

Through the proposed database architecture, three dimensional models, stored in a separated. NAS server, are available online via the open source WebGL based Potree viewer (Schutz, 2015). Potree is a point-based rendering solution specifically developed for visualizing large point clouds using standard web-based technologies. It is capable of easily providing a responsible interactive viewer that only requires a traditional web browser (WebGL enable), freeing the user from any configuration issue or specific software.

The selected viewer features the ability to (i) visualize 3D point clouds online, (ii) measure distance, compute volumes and areas, (iii) extract, visualize and download sections, (iv) link with external resources (metadata) through dedicated hot-spots located on the 3D interactive point cloud (Figure 10).

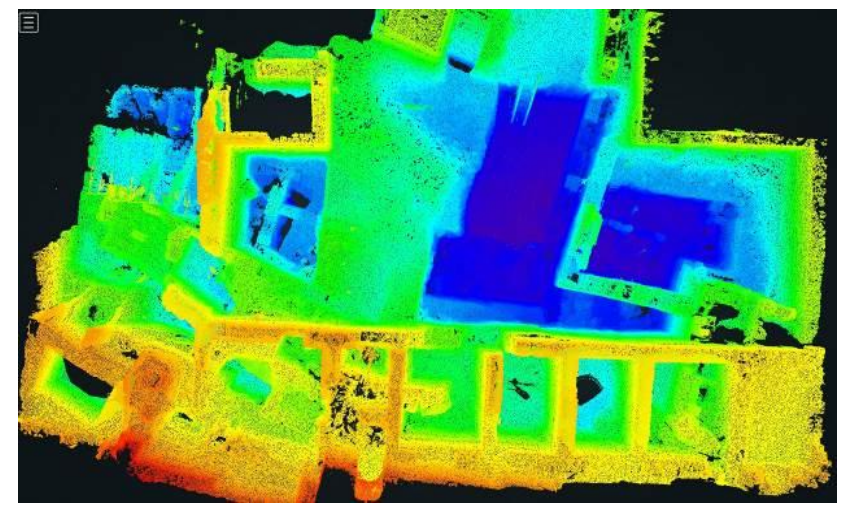

Figure 10: Potree Online Wiewer, Givati Parking Lot Excavation 3D Model, Elevation Map

Another layer of information is represented by the possibility to visualize High Resolution images online directly through the web browser without installing any additional plug in, and without any loss of quality. The system implemented supports JPEG/JPG, PNG, TIFF, GIF image formats. Large images are stored by creating an image pyramid using technique similar to frustum culling. High resolution images are subdivided into a set of tiles stored in subfolders which are visualized on the web browser according to the user input. The client's machine, hence downloads only data needed to create the current view, disregarding portions of the image outside the field of view.

Various measures have been implemented for the protection of IPR. Indeed, sharing online digital archives of 3D (Cultural Heritage) models still presents great challenges.

Different approaches (Koller, et al., 2004; Uccheddu, et al., 2004; Zhu, et al., 2008; Zagrouba and Jabra, 2009) were proposed to protect piracy, copies and misuse allowing interactive sharing. Still, the topic is heavily debated.

Potree point clouds files were encoded in an octree data structure using a dedicated converter (Schütz, 2014). All communications client-server will be performed using Hyper Text Transfer Protocol Secure (https) which guarantee a high level of content protection and security.

\section{CONCLUSIONS}

The dissemination of Open Access digital heritage content, through the implemented online platform, will aim at:

- creating a digital record of sites which will be then never lost forever;

- providing professionals, active in the cultural heritage domain, a scientific tool for study, conservation and valorisation purposes; 
- $\quad$ encouraging youth and educators to benefit from free, accessible historical and site online information;

- $\quad$ stimulating additional visit by tourists and invigorate communities from revenue from cultural tourism;

- $\quad$ sensitizing policy and decision makers on the topic of heritage at risk in order to undertake proper actions for its future and long term preservation and fruition.

\section{AKNOWLEDGEMENTS}

The authors acknowledge the valuable collaboration and support of the Cyprus Department of Antiquities and the Israel Antiquities Authority.

\section{REFERENCES}

Abate, D., Migliori, S., Pierattini, S., Jiménez FenándezPalacios, B., Rizzi, A., Remondino, F., 2012. Remote rendering and visualization of large textured 3D models. In: Proc. 18th IEEE Int. Conf. Virtual Systems and MultiMedia (VSMM) , pp. $399-404$.

Andujar, C., Boo, J., Brunet, P., Fairén, M., Navazo, I, Vázquez, P., Vinacua, A., 2007. Omni-directional relief impostors. In: Computer Graphics Forum 26(3), pp. 553-560,

Andujar, C.,. Brunet, P., 2008. Relief impostor selection for large scale urban rendering. In: IEEE Virtual Reality Workshop on Virtual Citiscapes: Key Research Issues in Modeling LargeScale Immersive Urban Environments.

Ben-Ami, D., 2014. Notes on the Iron IIA Settlement in Jerusalem in Light of Excavations in the Northwest of the City of David.Tel Aviv,41(1), pp.3-19.

Ben-Ami, D., Tchekhanovets, Y., (2011). The Lower City of Jerusalem on the Eve of its Destruction, 70 C.E.: A View from Hanyon Givati. In: BASOR 364, pp. 61-85.

Buchholz, H., Döllner, J., 2005. View-dependent rendering of multiresolution texture-atlases. In: IEEE Visualization, p. 215222

Chotzakoglou C. 2008, Religious Monuments in Turkishoccupied Cyprus: Evidence and Acts of Conitnuous Destruction, Nicosia

Cignoni, P., Di. Benedetto, M., Ganovelli, F., Gobbetti, E., Marton, F., Scopigno, R., 2007. Ray-casted blockmaps for large urban visualization. In: Computer Graphics Forum 26(3)

Coughenour, C., Vincent, M.L., 2015. Project Mosul: A Digital Future for Lost Heritage. In: WorldClassArcaeology, Special issue 72, , pp.10-11

Denard, H., 2012. A New Introduction to the London Charter. In Bentkowska-Kafel, A., Baker D., Denard H.,Paradata and Transparency in Virtual Heritage, Digital Research in the Arts and Humanities Series, pp.57-71

Di Benedetto, M., Cignoni, P., Ganovelli, F., Gobbetti, E., Marton, F., Scopigno, R., 2009. Interactive remote exploration of massive cityscape. In: Proc. of the 10th VAST Conference, pp. 9-16

El-Hakim, S.; Beraldin, J.; Remondino, F.; Picard, M.; Cournoyer, L.; Baltsavias, E., 2008. Using Terrestrial Laser
Scanning and Digital Images for the 3D Modelling of the Erechteion, Acropolis of Athens. In: Proceedings of DMACH Conference on Digital Media and its Applications in Cultural Heritage, Amman, Jordan, 3-6 November 2008; pp. 3-16

Fangi, G., 2015. Documentation of Some Cultural Heritage Emergencies in Syria in August 2010 by Spherical Photogrammetry. In: ISPRS Annals, Vol. II-5/w3, pp. 401-408.

Gibson, G.A., Van Meter, R., Network attached storage architecture, 2001. In: Communications of the ACM, Volume 43, Issue 11, pp. 37-45

Gobbetti, E., Marton, F., Cignoni, P., Di Benedetto, M., Ganovelli, F., 2006. CBDAM - Compressed Batched Dynamic Adaptive Meshes for terrain rendering. In: Computer Graphics Forum, Vol. 25(3), pp. 333-342

Gruen, A.; Remondino, F.; Zhang, L., 2004. Photogrammetric reconstruction of the Great Buddha of Bamiyan. In: The Photogrammetric Record, 19, 177-199

Guidi, G.; Remondino, F.; Russo, M.; Menna, F.; Rizzi, A.; Ercoli, S. 2009. A multi-resolution methodology for the 3D modelling of large and complex archaeological areas. In: Int. J. Architect. Comput, 7, 40-55.

Hadjilyra, M.A., 2009. The Latins of Cyprus. In: Cyprus Religious Groups.

Hadjisavvas, S., 2004. The Heritage of Cyprus Under Siege. In: Proceedings of the ICOMOS workshop Cultural Heritage at Risk in the Event of Armed Conflicts 20-24 February 2002. Skopje, pp.75-77.

Hermon, S., Nicolucci, F., Yiakoupi, K., Kolosova, A., Iannone, G., Faka, M., Kyriacou, P., Nicolucci, V., 2013. Documenting Architectonic Heritage in Confl ict Areas. The case of Agia Marina Church, Derynia, Cyprus. In: Built Heritage Monitoring Conservation Management, pp.800-808

H2020 Programme Guidelines on Open Access to Scientific Publications and Research Data in Horizon 2020, 2016. Available at: https://ec.europa.eu/research/participants/data/ref/h2020/grants_ manual/hi/oa_pilot/h2020-hi-oa-pilot-guide_en.pdf [Last Accessed: 17801/2017]

Jeffery, G., 1918. A Description of the Historic Monuments of Cyprus. In: Studies in the Archaeology and Architecture of the Island.

Jiménez Fernandez-Palacios, B., Remondino, F., Stefani, C., Lombardo, J. , De Luca, L., 2013. Web visualization of complex reality-based 3D models with NUBES. In: Digital Heritage International Congress (DigitalHeritage), pp. 701-704.

Kacyra, B., 2009. CyArk 500 - 3D Documentation of 500 Important Cultural Heritage Sites. In: Proceedings of the Photogrammetric week 2009, pp. 315-320

Kawano, H., 2013. Digital Archive Systems Using Cms and Gallery Tools - Implementation of Anthropological Museum. In International Journal of Heritage in the Digital Era, me 1, Supplement 1, Pages 125-130 
Koller, D., Tutitzin, M.,. Levoy, M., Tarini, M., Croccia, G., Cignoni, M., Scopigno, R., 2004. Protected interactive 3D graphics via remote rendering. In: Proceedings of ACM SIGGRAPH, pp. 695-703

Luhmann, T., Robson, S., Kyle, S., Boehm, J., 2014. CloseRange Photogrammetry and 3D Imaging.

McKenna, G., Stein, R., 2011. Lightweight Information Describing Objects (LIDO): The international Harvesting Standard for Museums. Available at: http://www.lidoschema.org/documents/LIDO-Booklet.pdf [Last Accessed: $17 / 01 / 2017$

Mills, J., 2011. 3D Laser Scanning for Heritage (second edition) Advice and guidance to users on laser scanning in archaeology and architecture

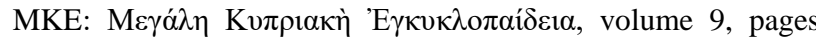
319-320, 1984-1991

Müller, E., U. Klosa, P. Hansson, S. Andersson, and E. Siira. 2003. Using XML for Long-term Preservation.. Available at: http://edoc.hu-berlin.de/etd2003/hansson-peter/PDF/index.pdf. [Last Accessed: 17/01/2017]

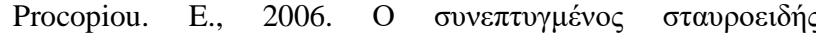

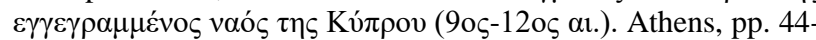
54. Available at: http://phdtheses.ekt.gr/eadd/handle/10442/21058 [Last Accessed: 17/01/2017]

Remondino, F., 2011. Heritage Recording and 3D Modeling with Photogrammetry and 3D Scanning. In: Remote Sens. 2011, 3, 1104-1138;

Remondino, F., Spera, M.G., Nocerino, E., Menna, F., Nex, F., 2014. State of the art in high density image matching. In: The Photogrammetric Record, Vol. 29(146), pp. 144-166.

Ronzino, P.,Hermon, S., Niccolucci, F., 2012. A Metadata Schema for Cultural Heritage Documentation, in V., Capellini (ed.), Electronic Imaging \& the Visual Arts: EVA 2012 Florence, pp. 36- 41.

Schutz, M., 2014. PotreeConverter - Uniform partitioning of point cloud data into an octree. Available at: http://potree.org/downloads/converter_documentation.pdf [Last Accessed: 15/12/2016]

Schutz, M., Wimmer, M., 2015. Rendering large point clouds in web browsers. In: Proc. 19th CESCG, pp. 83-90.

Silver, M., Rinaudo, F., Morezzi, E., Quendab, F., Moretti, M.L., 2016. The Cipa Database For Saving The Heritage Of Syria. In: The International Archives of the Photogrammetry, Remote Sensing and Spatial Information Sciences, Volume XLI-B5,

Smiley, D., Plugh, D.E., 2011. Apache Solr 3 Enterprise Search Server.

Ben-Ami, D., Tchekhanovets, Y., 2016. Then they built up the City of David with a high, strong wall and strong towers, and it became their citadel (I Maccabees 1:33). In: E. Meiron (ed.), City of David Studies of Ancient Jerusalem 11 (2016), pp. 19. 29.
Teijgeler, R., Preserving cultural heritage in times of conflict 2006. In: Preservation management for libraries, archives and museums. Edited by G.E. Gorman and Sydney J. Shep 2006, London: Facet Publishing p. 133-165

Toschi, I., Capra, A., De Luca, L., Beraldin, J.-A., Cournoyer, L., 2014. On the evaluation of photogrammetric methods for dense 3D surface reconstruction in a metrological context. In: ISPRS Ann. Photogramm. Remote Sens. Spatial Inf. Sci., II-5, $371-378$

Uccheddu, F., Corsini, M., Barni, M., 2004. Wavelet-based blind watermarking of 3D models. In: Proc. ACM Multimedia and Security Workshop, pp. 143- 154

Velios, A., 2011. The John Latham Archive: An Online Implementation Using Drupal. In: Art Documentation, Volume 30, Number 2, pp. 4-13

Vincent, M.L., Gutierrez, M.F., Coughenour, C., LopezMenchero Bendicho, V.M., Remondino, F., Fritsch, D., 2015. Crowd-sourcing the 3D digital reconstructions of lost cultural heritage. In: 2015 Digital Heritage, vol. 1, pp. 171-172. IEEE

Wenzel, K., Rothermel, M., Fritsch, D., Haala, N., 2013. Image acquisition and model selection for multi-view stereo. In: The International Archives of the Photogrammetry, Remote Sensing and Spatial Information Sciences, Volume XL-5/W1.

Will, T., Meier, H.R., 2007. Cultural Heritage and Natural Disasters: Risk Preparedness and the Limits of Prevention. In: Heritage at Risk Special Edition, Cultural Heritage and Natural Disasters Risk Preparedness and the Limits of Prevention, pp. 922

Yoon, Y., Gobbetti, E., Kasik, D., Manocha, D., 2008. Realtime massive model rendering. In: Synthesis Lectures on Computer Graphics and Animation (vol. 2)

Zagrouba, E., Jabra, S.B., 2009. A new approach of mesh watermarking Based on maximally stable meshes detection. In: Proceedings of the 3rd International Conference on New Technologies, Mobility and Security (NTMS), pp.1-5

Zhu, J., Bakdash, J.Z., Koller, D., Banton, T., Proffitt, D.R., Humphreys, G., 2008. Quantifying usability in secure graphics: assessing the user costs of protecting 3D content. In: Proc. of the Symposium on applied Perception in Graphics and Visualization (APGV) 